\title{
Phase angle thermography with ultrasound burst excitation
}

\author{
by A. Dillenz, Th. Zweschper, and G. Busse
}

University of Stuttgart, Institute of Polymer Testing and Polymer Science (IKP), Department of NonDestructive Testing

Pfaffenwaldring 32, D-70569 Stuttgart, Germany, E-mail: dillenz@ikp.uni-stuttgart.de

\begin{abstract}
Elastic wave phase thermography with ultrasound burst excitation is a technique derived from the well known Ultrasound-Lock-In thermography and pulse phase thermography thereby resulting in a robust and fast measuring method. The advantage of multifrequency thermal waves is combined with the defect-selectivity provided by ultrasound elastic wave phase thermography where phase evaluation of temperature images suppresses inhomogenities in material emissivity. At the same time it avoids the disadvantages of Ultrasound Lock-In Thermography with respect to measuring time, reproducibility, and applicability.
\end{abstract}

\section{Introduction}

Defect selective non-destructive testing methods are appreciated for applications in aerospace and related fields. The main advantage is the clarity in interpretation of such dark field methods: they show only the defects themselves. Therefore such methods can be applied by maintenance staff and not only by well trained specialised experts. Ultrasound Lock-in thermography is one example of an established defect selective testing method [1,2].

However, a characteristic of the Lock-in technique using the four point algorithm for phase evaluation is the need for a sinusoidal excitation signal [3]. That is no problem if remote excitation is used like absorption of radiation or convective heating. However, elastic wave excitation presumes mechanical coupling between the ultrasound source and the sample. That can cause problems since the pressure between excitation source and sample must be kept constant during the whole measuring cycle. This is difficult to achieve in some cases over the whole Lock-in period that can last up to minutes, depending on the required range [4]. A solution could be the use of short burst signals for sample excitation followed by a cooling down period. The spectral components of that signal provide information about defects in almost the same way as the Lock-in technique but with an improved robustness against coupling problems and a reduced measuring duration. As not only single thermography images are evaluated, but rather their complete time sequence (by using a Fourier transformation) the whole available information is compressed to result in one frequency-dependent phase and amplitude image thereby improving the signal-to-noise ratio considerably. This way a much better detectability of defects is achieved as compared to just one thermography image taken from the sequence while all others are ignored.

This way the pulse excitation with phase evaluation can combine the advantages of Lockin and pulse thermography. That kind of evaluation technique using Fourier or Wavelet transformations was shown to be applicable to flash light excited thermography $[5,6,7]$. The combination of ultrasound burst thermography with Fourier phase evaluation is described in this paper. These evaluation procedures require an arithmetic performance which is provided by modern personal computers.

\section{Thermal waves and Fourier transform}

Active thermography is based on heating up a sample and monitoring its thermal response with an infrared camera. This way hidden structures can be revealed. One well known method is pulse thermography where flash lamps are used to generate short heat pulses and where the obtained time sequence of thermal images is inspected [8]. A disadvantage of this method is the fact that inhomogenities in the sample heating appear in the resulting thermal image and make interpretation more difficult. 
An improvement is the Lock-in Thermography [3,9-11] which is implemented in the AGEMA 900 Thermovision system. A sinusoidal thermal wave is generated on the whole sample. As the thermography signal also has a sinusoidal shape, the amplitude and phase can be calculated using the simple and fast four point Fourier algorithm [3]. The phase angle image has the advantage that it has more range [12-14] and that it is independent of local variations of heat distributions or of surface emissivity [15].

This evaluation method was also used successfully in connection with ultrasonic excitation. In the resulting ultrasound Lock-in thermography $[1,2,4]$ the phase information is important since the coupling of the ultrasonic source is spatially confined to a small area and causes a strong temperature gradient across the sample (even if standing mechanical waves are avoided, e.g. by frequency jitter). To suppress this effect the phase image is an adequate means. Additionally, the phase image contains information about the depth where the defect is located [16].

\subsection{Transient signals}

Transient signals differ from sinusoidal signals by the fact that their spectrum contains not just one frequency. If a sample is heated with an ultrasound burst and if both the heating and the subsequent cooling process are recorded with the infrared camera, then phase and amplitude information can be derived from the Fourier transform of the local time sequence.

The Fourier transform of a periodical time signal $\mathrm{f}$ is denoted by

$$
F(\omega)=\sum_{t} f(t) \exp (i \omega t)
$$

where $\omega$ is the transformation frequency.

The frequency spectrum of phase $\varphi$ is given by the complex Fourier transform:

$$
\varphi(\omega)=\arctan \left(\frac{r e(F(\omega))}{\operatorname{im}(F(\omega))}\right)
$$

If this transformation is performed at various frequencies one obtains images that are similar to Lock-In thermography images taken at the same frequencies. A burst signal and the thermal response on the sample can be seen in figure 1, left. The burst with a duration of $100 \mathrm{~ms}$ causes a steep rise in sample temperature and a subsequent slow decay (figure 1 , right). The spectrum obtained at a damaged region of the sample is shown in figure 2, left. There are frequency components ranging from $0 \mathrm{~Hz}$ up to $4 \mathrm{~Hz}$ while the spectrum taken at an undamaged part of the sample contains noise only (figure 2, right).

\section{Experimental set-up}

The experimental set-up for elastic wave phase thermography is shown in figure 3 . It is based on the set-up for ultrasound Lock-in thermography described previously [1] (and used later on for acoustic pulse excitation $[2,17]$ ), but extended with a sequence recorder and a MATLAB evaluation module for the Fourier transformation and subsequent evaluation. An ultrasonic transducer is attached to the sample and acts as a heat generator (by converting elastic energy to thermal energy due to hysteresis-effects $[18,19])$. The infrared camera monitors the resulting thermal signal on the sample surface. A control unit synchronises the infrared camera with the ultrasound source operating at $20 \mathrm{kHz}$. The burst duration typically ranges from $100 \mathrm{~ms}$ up to a few seconds. The whole measurement is performed within several seconds.

Though the elastic wave source is rated up to $2 \mathrm{~kW}$, there are losses due to the coupling between sonotrode and sample thus leading to a typical acoustic power between $10 \mathrm{~W}$ and $200 \mathrm{~W}$ injected into the inspected sample. 


\section{Experimental results}

We applied elastic wave phase thermography to several kinds of samples: fibre reinforced polymers, metallic structures, and riveted structures. Some representative examples are presented here.

\subsection{Detection of crack in a riveted aluminium sample}

Figure 4 a) shows a cut-out from a metallic aircraft wing which is reinforced by a riveted stringer. A fine crack had been found along the rivet row, growing between the rivet boreholes. For examination with elastic wave phase thermography, ultrasound power of $2 \mathrm{~kW}$

was applied for $100 \mathrm{~ms}$. The subsequent cooling down was recorded for less than 3 seconds with a frame rate of $15 \mathrm{~Hz}$. A Fourier transformation at a frequency of $0.83 \mathrm{~Hz}$ provided phase and amplitude images.

When applying ultrasound to the sample, the crack heats up due to friction between the crack edges and can be seen in the thermography image taken $270 \mathrm{~ms}$ after heating (figure $4 b)$. The crack signal is not very clear since the noise is relatively high in a single thermography image. Also, there is a temperature gradient in the sample, the temperature has a maximum at the upper part of the sample where the ultrasonic excitation is located. These effects make it difficult to interpret the thermal image clearly.

The achieved improvement can be seen in the Fourier amplitude image derived from the same frequence (figure 4c), where the signal-to-noise ratio is much better. However, the best result with respect to noise and resolution is obtained in the phase image (figure 4d) since the temperature gradient disappears completely so that only the defect is imaged.

\subsection{Detection of cracks in ceramic coating}

Turbine blades are often coated with ceramics to protect the steel substrate from corrosion. As the ceramic coating is vulnerable and cracks in the coating can lead to fatal damages in the steel substrate, there is a need for non destructive testing. Approaches using ultrasound Lock-in thermography failed since the very thin coating layers require modulation frequencies above the range of the AGEMA Lock-in module. One way out is to use short ultrasound bursts to excite high frequency thermal waves. The result of exciting the blade with 2 $\mathrm{kW}$ for $100 \mathrm{~ms}$ is the thermography image approximately 1 second after the heat pulse (figure 5a). Here, again, the phase image (figure $5 \mathrm{c}$ ) shows the advantage of suppressing even strong thermal gradients that appear in the amplitude image (figure $5 \mathrm{~b}$ ) and the thermography image (5a).

\subsection{Characterisation of damage in carbon fibre reinforced plastic plates}

Characterisation of thick fibre reinforced plastic plates is a difficult task due to the anisotropy of physical properties of this kind of materials. The penetration of thermal waves is limited and depends strongly on the fibre direction. Ultrasound excitation is useful for such samples since the penetration depth for light excited active thermography is limited to a depth range of few millimetres while ultrasound Lock-in thermography can reveal even deep defects [20]. Here, the burst excitation technique is compared to the Lock-in technique. Figure 5 $\mathrm{a}, \mathrm{b}$ and $\mathrm{c}$ are evaluations of one single measurement with an ultrasound power of $2 \mathrm{~kW}$ injected during a burst length of $100 \mathrm{~ms}$, and an overall measurement duration of 30 seconds.

Figure $5 \mathrm{~d}$ shows for comparison the result of an ultrasound Lock-in thermography measurement performed with $400 \mathrm{~W}$ and a measurement duration of 99 seconds.

A description of the defects inserted in the sample is given in figure 5 where (1) and (2) are two delaminations in different depths, (3) is a near-surface slight impact and (4) is a heavy impact damage ranging from the surface through the whole sample thickness. The penetration depth with elastic wave phase thermography is sufficient to show even the deep delamination (2). The different depths of delaminations (1) and (2) are indicated by the related different phase angles. The heavy impact (4) can clearly be seen but the small nearsurface impact is hard to detect. Figure $5 \mathrm{~b}$ shows a higher evaluation frequency of $0.1 \mathrm{~Hz}$. Here the near-surface impact appears clearer and the delaminations are still visible. With an 
evaluation frequency of $1 \mathrm{~Hz}$ only the near-surface impact can be seen. Thus a depth profile of the impact damages can be generated. The comparison with the ultrasound Lock-in thermography image (figure $5 \mathrm{~d}$ ) shows that the signal-to-noise ratio with pulse excitation is even better and the defects appear much more clearly.

\section{Summary}

Phase angle thermography with ultrasound burst excitation preserves the advantages of ultrasound Lock-in thermography while it improves the robustness as well as the inspection speed. The measuring time is reduced clearly by the use of burst excitation since several frequencies are contained in just one measurement. The use of the Fourier analysis provides all the advantages of phase images known from Lock-in thermography. Further improvements are being achieved in our lab by using a focal plane array camera with high frame rates and a better NETD.

\section{Acknowledgements}

The authors are grateful to DLR Stuttgart and Luftwaffenwerft 13, Erding for cooperation and providing samples.

\section{References}

[1] WU, D.; SALERNO, A.; RANTALA, J.; BUSSE, G.: Characterization of layered materials using lock-in thermography. 9th International Conference on Photoacoustic and Photothermal Phenomena, Nanjing, China. Progress in Natural Science, Supplement to Vol. 6 (1996) pp.76-79

[2] DILLENZ, A.; SALERNO, A.; WU, D.; RANTALA, J.;, BUSSE; G.: Progress in ultrasonic lockin thermography. Quantitative infrared thermography, QIRT 98, Lodz, Polen. Akademickie Centrum Graficzno-Marketingowe Lodart S.A., Lodz.(1999), pp. 154-160. ISBN 83-8720288-6

[3] BUSSE, G., WU D. AND KARPEN W.: Thermal wave imaging with phase sensitive modulated thermography. In: J. Appl. Phys. Vol. 71 (1992): pp. 3962-3965.

[4] DILLENZ, A.; BUSSE, G.; WU, D.: Ultrasound lock-in thermography: feasibilities and limitations. In: Diagnostic imaging technologies and industrial applications. SPIE Vol. 3827 (1999) S. 10-15.

[5] MALDAGUE, X.; MARINETTI, S.; "Pulse Phase Infrared Thermography," J. Appl. Phys, 79 [5]: 2694-2698, 1 March 1996.

[6] GALMICHE, F. ; MALDAGUE, X. ; "Pulsed Phased Thermography with the Wavelet Transform", QNDE, Montreal,(1999).

[7] MALDAGUE, X.; MARINETTI, S.; BUSSE, G.; COUTURIER, J.-P.: Possible applications of pulse phase thermography. Progress in Natural Science. Supplment to Vol. 6, December 1996, S. 80-82

[8] THOMAS, R. L.; FAVRO, L.D.; KUO, P. K. ; AHMED, T.; XIAOYAN Han, LI Wang, XUN Wang and SHEPARD, S.M.; Pulse-Echo Thermal-Wave Imaging for Non-Destructive Evaluation, Proc. 15th International Congress on Acoustics, Trondheim, Norway, June 26-30, 1995, pp. $433-436$.

[9] G. M. CARLOMAGNO, P. G. BERARDI, Unsteady thermotopography in non-destructive testing, Proc. 3rd Biannual Exchange, St. Louis/USA, 24.-26. August 1976, pp. 33-39. 
[10] BEAUDOIN J. L.; MERIENNE E.; DANJOUX R.; EGEE M.: Numerical system for infrared scanners and application to the subsurface control of materials by photothermal radiometry, Infrared Technology and Applications, SPIE Vol. 590 (1985) p. 287

[11] KUO, P.K.; FENG Z. J.; AHMED T.; FAVRO L. D.; THOMAS R. L.; HARTIKAINEN J.: Parallel thermal wave imaging using a vector lock-in video technique. In: Photoacoustic and Photothermal Phenomena, ed. P. Hess and J. Pelzl. Heidelberg: Springer-Verlag. (1987) pp. 415-418.

[12] BUSSE G.: Optoacoustic phase angle measurement for probing a metal. In: Appl. Phys. Lett. Vol. 35 (1979) pp. 759-760.

[13] THOMAS, R. L., J. J. POUCH, Y. H. WONG, L. D. FAVRO, P. K. KUO and A. ROSENCWAIG. "Subsurface flaw detection in metals by photoacoustic microscopy." J. Appl. Phys. Vol. 51 (1980): p1152-1156.

[14] LEHTO A.; JAARINEN J.; TIUSANEN T.; JOKINEN M.; LUUKKALA M.: Amplitude and phase in thermal wave imaging. In: Electr. Lett. Vol. 17 (1981): pp. 364-365.

[15] ROSENCWAIG A.; BUSSE G.: High resolution photoacoustic thermal wave microscopy. In: Appl. Phys. Lett. Vol. 36 (1980): pp. 725-727.

[16] DILLENZ, A.; WU, D.; BREITRÜCK, K.; BUSSE, G.:Lock-in thermography for depth resolved defect characterisation. WCNDT2000, Rome (in press)

[17] FAVRO, L. D.; XIAOYAN Han; ZHONG Ouyang; GANG Sun; HUA Sui; THOMAS R. L.; Infrared imaging of defects heated by a sonic pulse; Rev. Sci. Inst. 71, 6 (2000): pp. 24182421.

[18] MIGNOGNA R. B.; GREEN R. E., Jr.; DUKE; HENNEKE E. G.; REIFSNIDER K.L.: Thermographic investigations of high-power ultrasonic heating in materials. In: Ultrasonics 7 (1981) pp. 159-163

[19] STÄRK F.: Temperature measurements on cyclically loaded materials. In: Werkstofftechnik 13, Verlag Chemie GmbH, Weinheim (1982) pp. 333-338

[20] ALMOND, D. P. ; BALL, R. J.; DILLENZ, A.; BUSSE, G. ; KRAPEZ, J.-C.; GALMICHE, F. ; MALDAGUE, X.: Round Robin comparison II of the capabilities of various thermographic techniques in the detection of defects in carbon fibre composites. QIRT Reims (in press)
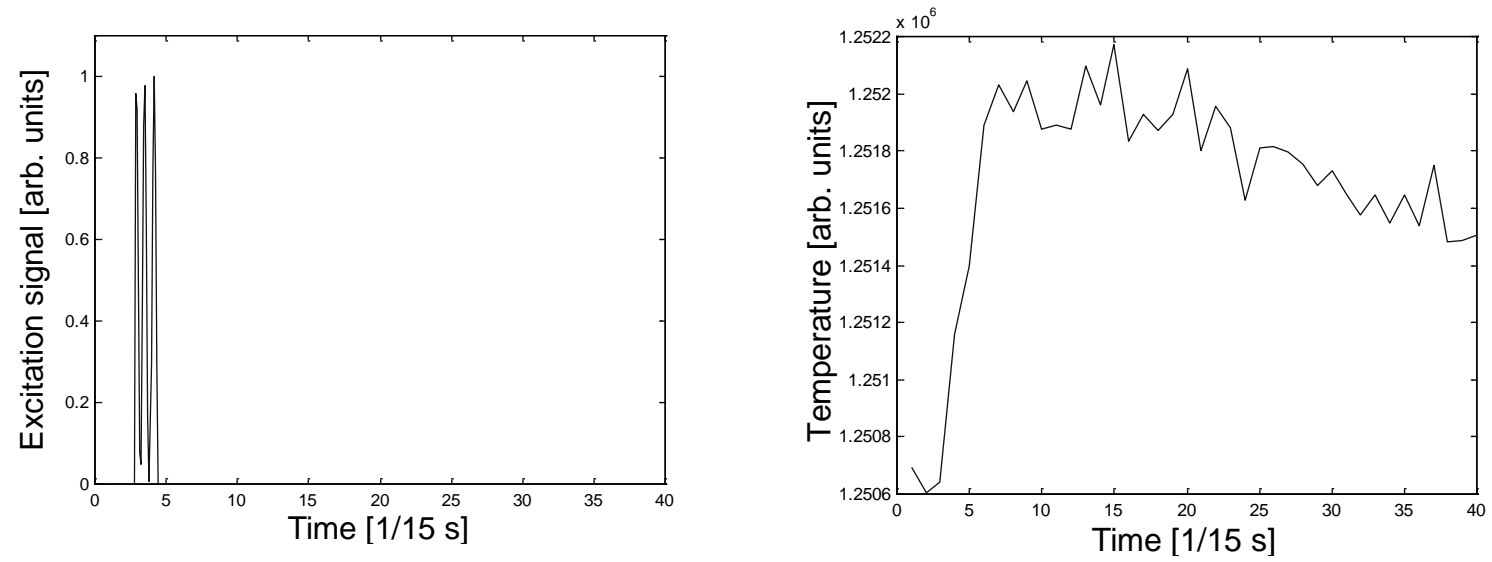

Figure 1: Ultrasonic excitation signal (left) and thermal response. 

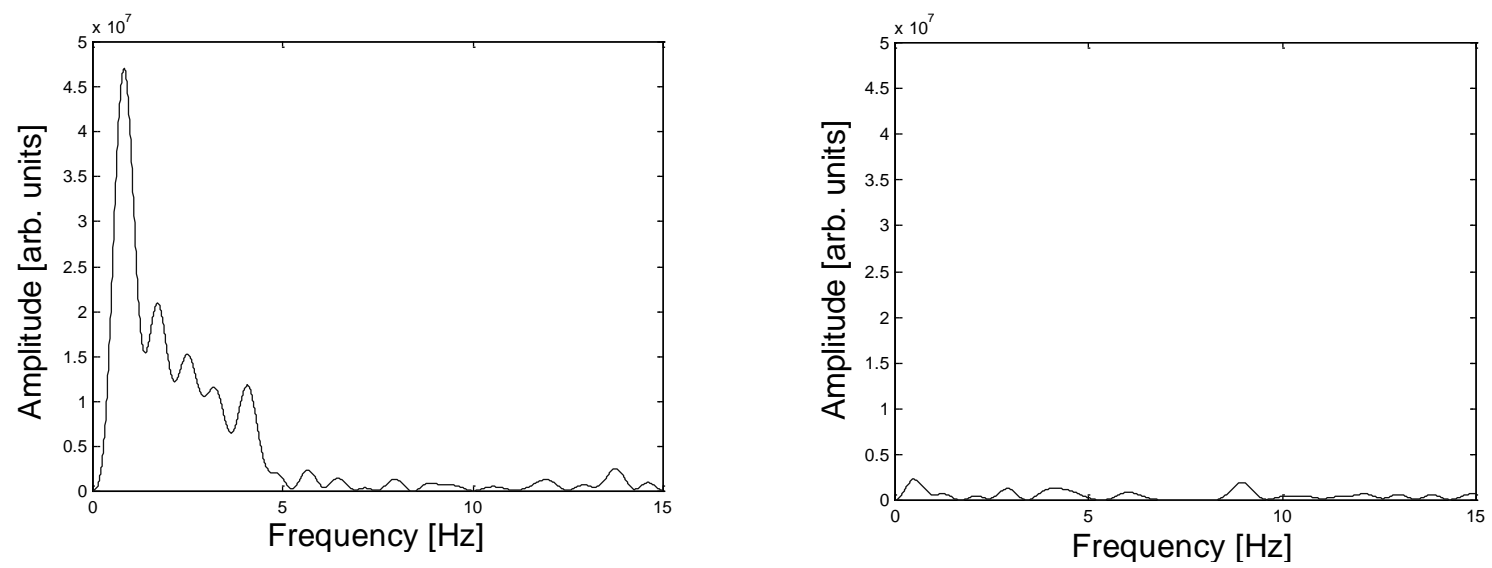

Figure 2: Spectrum of damaged (left) and undamaged part of aluminium sample shown in figure 3.

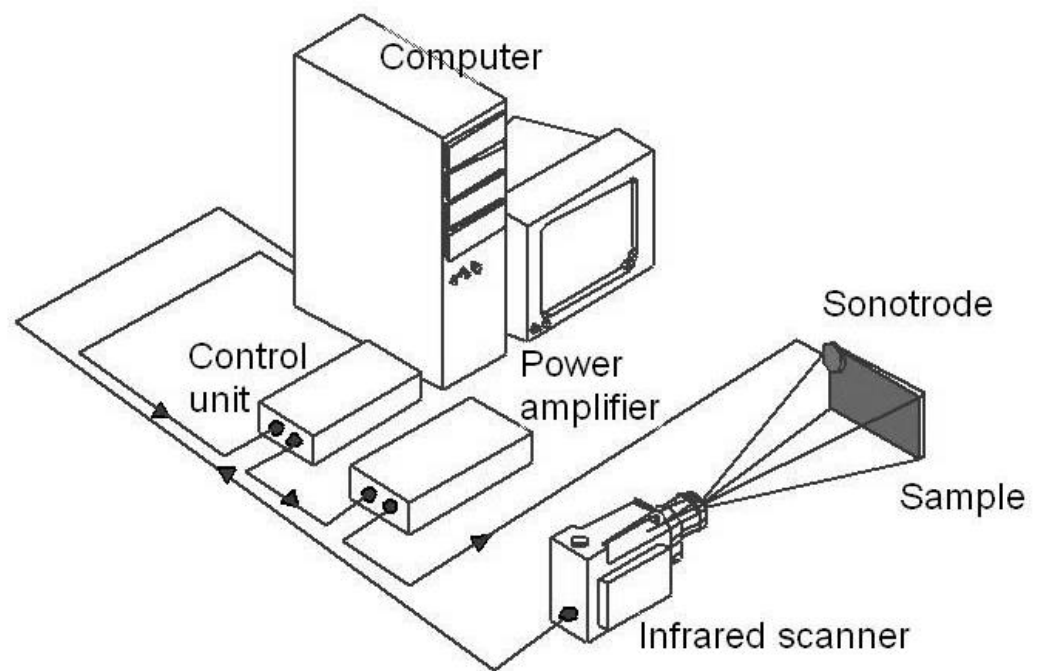

Figure 3: Experimental arrangement of thermography with ultrasound burst excitation.

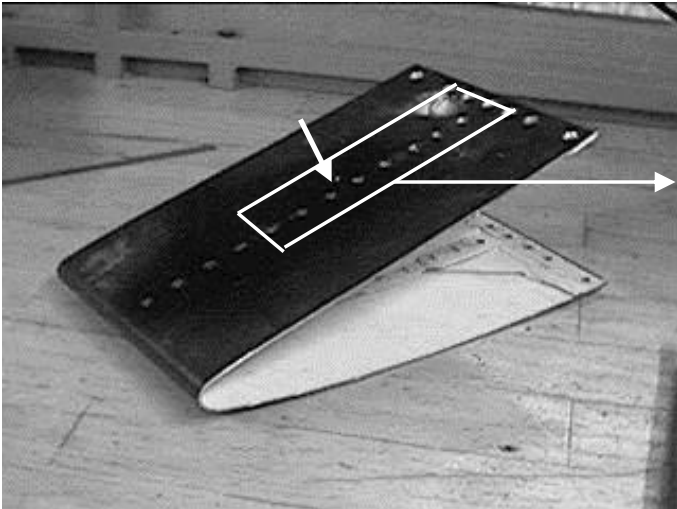

(a) photo

Figure 4: Aluminium sample with crack along rivet row. Only the marked area is shown in the thermal images. The crack is indicated by white arrows. Thermography image (b) taken $270 \mathrm{~ms}$ after heating pulse, (c) Fourier amplitude image and (d) phase image at $0.83 \mathrm{~Hz}$.

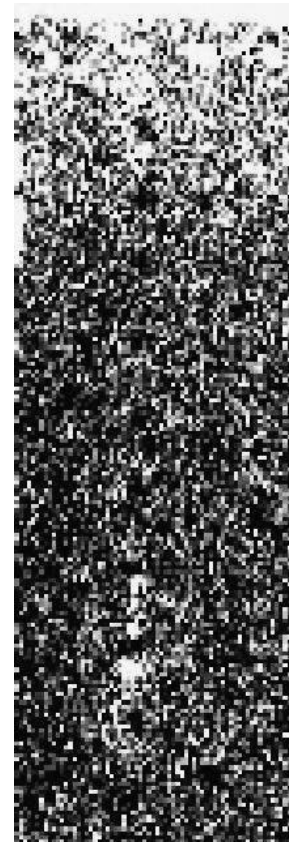

(b) thermal

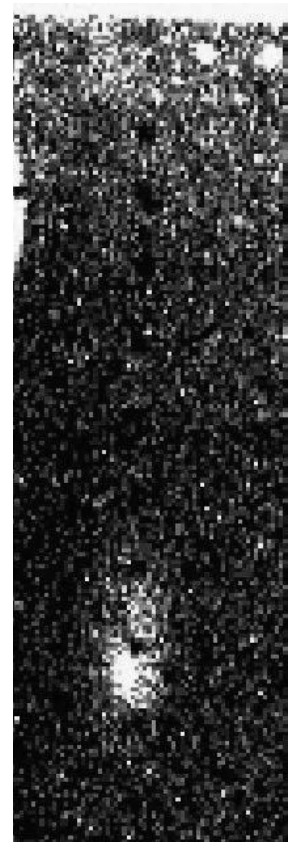

(c) amplitude

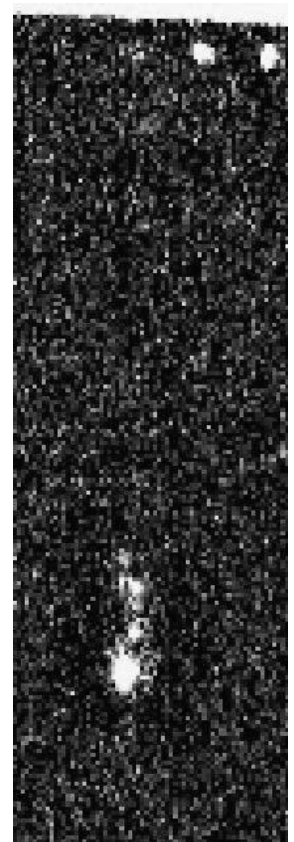

(d) phase 


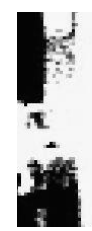

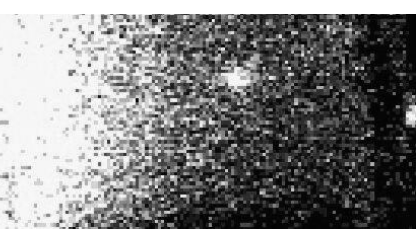

(a) thermal

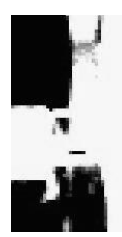

(b) amplitude

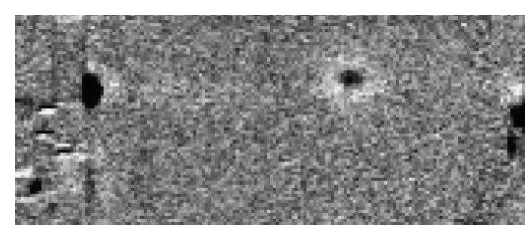

(c) phase

Figure 5: Turbine blade with a crack in the ceramic coating. Thermography image (a) taken $1 \mathrm{~s}$ after ultrasonic burst, Fourier transform images at $0.24 \mathrm{~Hz}$ of amplitude(b) and phase(c) .

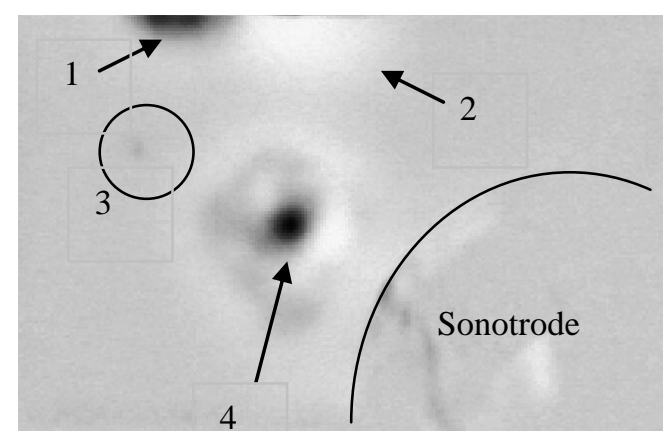

(a) $0.02 \mathrm{~Hz}$

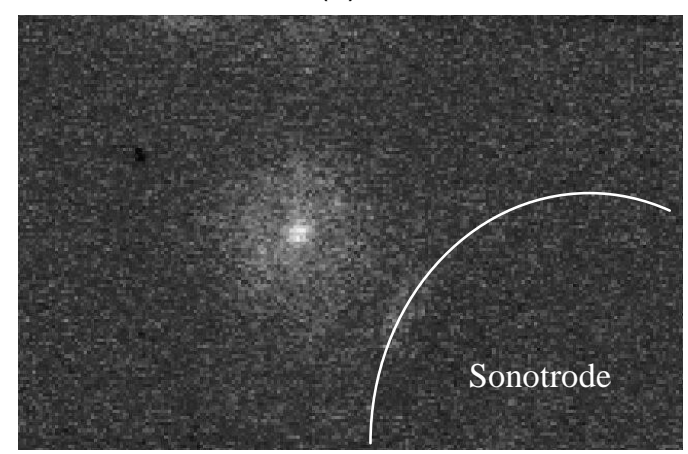

(c) $1.0 \mathrm{~Hz}$

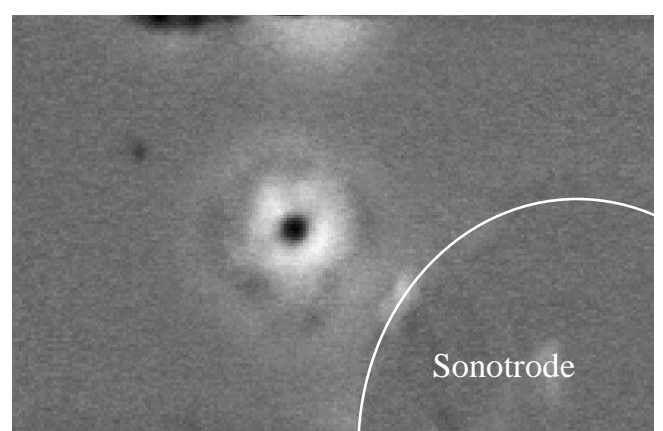

(b) $0.1 \mathrm{~Hz}$

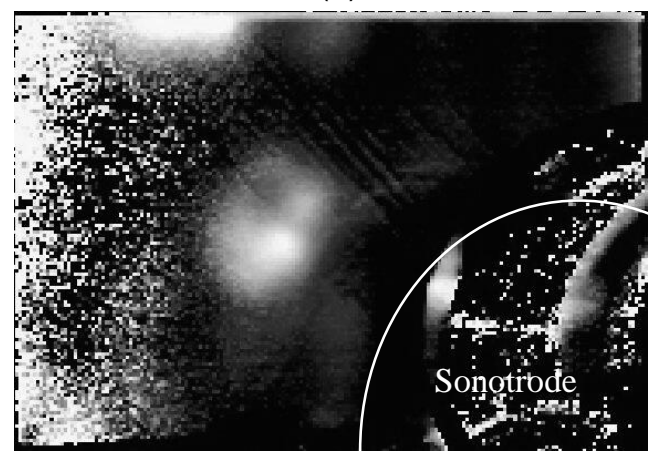

(d) Lock-in $0.029 \mathrm{~Hz}$

Figure 6: Ultrasound burst thermography phase images of CFRP plate with three different defects at different evaluation frequencies $(a, b, c)$ and with ultrasound Lock-in thermography (d).

Description of damages denoted in figure 5 a: Delamination in $1.5 \mathrm{~mm}$ depth (1) and of $4 \mathrm{~mm}$ depth(2), near-surface impact (3), and heavy impact (with tree structure) (4) 